\title{
Money, Capital and Rationality
}

\author{
Weiyu $\operatorname{Pan}^{1 *}$ \\ ${ }^{1}$ Southwestern University of Finance and Economics, Chengdu, China \\ *Weiyu Pan, E-mail: Panweiyu1990@qq.com
}

Received: October 2, 2017

doi:10.22158/rem.v2n5p192
Accepted: October 15, 2017 Online Published: October 17, 2017

URL: http://dx.doi.org/10.22158/rem.v2n5p192

\begin{abstract}
One of the basic modern society's characteristics lies in the manifestation of rationality. All the phenomena could be interpreted through reason and rationality becomes the highest standard of measuring and assessing the production and livelihood. However, the combination of capital and rationality has become the capital rationality in capitalist society. Through the study of the internal correlation between commodity, money and capital, Marx found that this combination only cares about how to obtain more capital and it is not for human purpose, which leads to alienation among people. The limitations of capital rationality will inevitably bring a rational crisis. An important enlightenment that Marx's research gives to us is that we mustn't allow the capital rationality to rule over the human beings.
\end{abstract}

\section{Keywords}

capital, money, rationality, dialectical logic, marxism

\section{Introduction}

Nowadays people regard rationality as one of the most important principles of life. And the rationality is measured by returns of capital. Since money is the most common form of capital in daily life, studying money is significant to understand the principle of rationality. On the one hand, the increase of money depends on the rationality under the capitalist mode of production. On the other hand, it is likely that people become the real proletarian that leads to non-rational risk.

\section{Rational Life Based on Money}

\subsection{From Commodity Form to Monetary Form}

As Marx once said that we can only understand the essence of money by starting to look at commodities first. The value of commodities reflects abstract human labor, embodies social relationships and therefore inhabits social attributes. Value is intangible and can only be reflected if there is a medium, leading to the birth of a monetary form. However, there is a paradox between commodity form and monetary form: they cannot exist simultaneously. Commodities are thus sold not 
for the purpose of buying other commodities but in order to replace commodity-form by money-form. The transformation mentioned above is from $\mathrm{C}-\mathrm{M}-\mathrm{C}$ to $\mathrm{M}-\mathrm{C}-\mathrm{M}$. This transformation doesn't only implicate the transformation of forms, but the transformation of the value system as well, making money itself the goal instead of commodity. However, because money itself doesn't hold any value, there must a surplus of money after the transformation. Thus $M-C-M+\triangle M$ is the prerequisite of $\mathrm{M}-\mathrm{C}-\mathrm{M}$ 's existence. Based on this fact, Marx pointed out that: "Money begins to serve as means of payment that is beyond the sphere of circulation of commodities when the production of commodities has sufficiently extended itself. It becomes the commodity that is the universal subject-matter of all contracts". This transcendence of money enables us to measure everything in this world by money. "Since one cannot see from money itself what has been transformed into it, everything, commodity or not, can be converted into money and everything becomes sellable and buyable. Its circulation became the great social distillery. Everything that is thrown inside comes out as a "crystal money"'.

\subsection{The Universal Fate of Money As Media}

Marx once praised Shakespeare excellently depicts the real nature of money. Regarding social intercourse, the linkage of man to anything must be facilitated by a medium. In reality, what really functions as a intermediary is not some spiritual ability, but money. In "Timon of Athens", Shakespeare said "This yellow slave will knit and break religions, bless the accursed, make the hoar leprosy adored, place thieves and give them title, knee and approbation with senators on the bench: this is it that makes the wappen'd widow wed again..." To better understand the essence of money, Marx worked with another masterpiece "Faust" and concluded that money is the medium of all mediums. How much money people own equals how much power they have. In the same way a rich man can marry the most beautiful women although he might be ugly, foolish people can hire talented people work for them. And even the most dishonest can be the most trusted. Money is the bond of all bonds, the link connecting human beings and society, nature. People gain beauty, wisdom, honesty and other intangible or tangible things. It can change everything impossible to being possible. Because it's sufficient to simply pursue money, the characteristics of human beings gradually disappear, and all that's left are the characteristics of money.

Therefore, Marx restated two most important properties of money emphasized in "Timon of Athen":

(1) It is the visible divinity - the transformation of all human and natural properties into their contraries, the universal confounding and distorting of things: impossibilities are soldered together by it.

(2) It is the common whore, the common pimp of people and nations.

Hence, there is no difference between human beings and commodity under capitalist form of production, which means all men are equal in front of money. That also means that the form determines everything. Everything that doesn't correspond to that form, will be eliminated. This change/transformation renders unimportant what kind of human somebody is. It is how much money you have that determines the prospect of one's relationship to society. Under these conditions, it is sufficient, to take on life via rational calculation. Therefore, this kind of equality is only valid within 
the framework of this form.

\subsection{The Capital and the Essence of Human Beings}

\subsubsection{The Essence of Human Beings}

Human beings function like commodities under capitalist production mode. Relationships between men have become the same as relationships between things. However, "Man's essence is not an abstract thing inherent to single individual. In reality, it is the sum of all social relations". So what kind of social relations would be present under such circumstance? And what kind of reality does man's nature reflect? As Marx once said, "capital is not a thing, but a social relation between people, established by things acting as intermediary". Considering that all relations are agented by money and money is translated into capital under this kind of production mode, thus the essence of human beings can be referred to as capital in the end. By reflecting on the essential definition of capital-surplus value and how it is created, one can also see: Looking at the general formula for capital, $G-W-G$ ' to $G-W-G+\triangle M$, the only difference between the beginning and the end is the change of quantity of money (or the quantity of capital). Due to money being the material bearer of value, and value being drawn from abstract labor, abstract labor determines real production. The key to understand abstract labor lies in how and how much the human labor can be recognized (or admitted) by the society. The answers to these two questions rely on rationality. That is, only when it follows the form of rationality can human labor be recognized.

As a result, the qualitative contents are dropped out by rationality standard, the only thing left is the quantitative form, the so-called "gold-crystal". Thus, the alienation is holistic and implicates complete separation of form and contents. Under this circumstance, what really matters are roles human beings play, such as capitalists, workers, creditors and debtors, but not who people are. That is the reason why Karl Marx, in his work The Capital, focuses more on the roles of human beings rather than on the human itself. Therefore, he repeatedly emphasized, one cannot derive the qualities of a person from the qualities of his or her role. One can't even make conclusions about the qualities of certain types of persons based on the role played. However, it also means people with different qualities become commodities labelled with different tags.

\subsubsection{The Alienation of the Essence of Human Beings}

However, the reality of human beings' nature is intangible. Marx once said "It is the fantastic realization of the human essence since the human essence has not acquired any true reality". But why is the human essence a fantasy? Social relationships are created by human beings and they would change with whenever the production mode changes. This changeability of social relationships at any time make it impossible to be the real essence of man. Because capital is the expansion of the monetary form, one can also look back on the description of capital in Shakespeare's Timon of Athens, it also indicates the characteristic of alienation. On the one hand, capital is the "visible divinity" which bonds the whole society, all connections of man is established by capital (medium). On the other hand, capital is the "common whore" which estranges people from each other. 
With the continuous expansion of the capitalist mode of production, the medium function of capital also extends gradually. As a result, materialistic relations between human beings become tighter and tighter. However, the closer the materialistic relations between individuals become, the more distant people become from each other and from their own nature. Neither common people nor the elite, neither family or nations can flee from this transformation, but have no choice to accept it. It is the universal fate of modern society. Therefore, Marx pointed out that capitalist mode of production would run forever like a perpetual motion machine without external supports. Because it (capitalist mode of production) is autonomous and can adjust itself based on rational principles, it can even keep circulating when met with a financial crisis. For example, Rosa Luxemburg bitterly complained, in Capital Volume II, that "accumulation, production, realization and exchange run smoothly with clockwork precision", adding ironically (given the way that Marx calculated, not always correctly, tedious arithmetic examples of expanding accumulation from one year to the next) that "no doubt this particular kind of 'accumulation' can continued infinitum, just as long, that is to say, as ink and paper do not run out". Therefore, a single factor financial crisis cannot wipe out capitalism. In other words, there must be other forces behind a financial crisis if capitalism is to be replaced. To find out what these forces are, we must ask what benefits we actually by further running this rational production mode.

\section{How Rational Principles Work}

\subsection{Thing-in-Itself and Specters Outside the Domain}

As mentioned above, capital separates the forms and contents of everything in society based on rational rules, making forms superior than contents in the meanwhile. So, rationality is one way to comprehend forms. But there is one question we should pay attention to: Where are the contents dropped out by rationality? In order to answer this question, we need go back to the age of classical philosophy.

Capitalist mode of production has been accepted widely by the whole society already before the age of German classical philosophy. Rationality has become the principle of life and people universally hold the opinion that everything can be explained by rationality. However, humans seemingly never could get a complete understanding of life. During the French Revolution and with the continuous development of capitalism, people began to question life: What is the significance of human beings' lives? Kant was the first person who replied to this question in a philosophical way. Thereby Kant raised the concept of the "thing-in-itself" based on the Antinomy. This concept does not only draw borders for rationality and leaves room for beliefs. It also implicates that in this world there are things which can't be understood by applying rationality. Kant's "thing-in-itself" is a broader concept which admits that rationality is not omnipotent. For example, matters like the existence of gods or souls. This cannot be explained by rationality, Kant places them into his "thing-in-itself"-concept, thus they are intangible and do not take up any real "space". Therefore, "thing-in-itself" is outside the domain of rationality. For example, one person is willing to work, but his work (labor) cannot be admitted by the forms restricted by rationality. Then his labor becomes "thing-in-itself". Such workers are called 
"specters outside the domain" by Marx. They are proletarian outside the labor-relation, who are not considered by some economic scholars.

\subsection{Non-Rational Risk Caused by Rationality}

Compared to Kant's thing-in-itself, Hegel raised a new concept: "Substance is subject", which means there is only the sphere of life and no other space for "thing-in-itself". Therefore, substance, as a single form, would be fixed as a rule. Then it is limited to subjective truth, phenomena, and appearances, making "substance is subject" a limited truth. However, forms and contents, as two sides of one thing, really exist. That indicates Antinomy cannot give answers to holistic questions merely based on parts. In the same way, rationality of human beings cannot be used to explain everything in life. Human beings must accept the matters that are beyond rationality. Although their existence might not be acknowledged, they do exist in reality.

Therefore, the accumulation of non-rational factors is exactly same as the accumulation of capital under the capitalist mode of production. The only difference is, since non-rational factors cannot be understood rationality, they become mysterious and wouldn't acknowledged. Applying this to labor factor would mean that individual labor can't be acknowledged if it cannot be converted into social labor. What is more, quantitative change will finally result in qualitative change according to the General Formula for Capital $\mathrm{G}-\mathrm{G}^{\prime}$. Thus, it is likely that if modern society develops according to this mode, it will inevitably lead to a crisis of non-rationality.

\section{Conclusion}

Although Marx didn't clearly state how to step out from this predicament, it's reasonable that the capitalist mode of production finds itself within it. However, he pointed out that the key to is following: Make man be man. Only if man don't need any "medium" to understand life, unfold all social relations between man, then life will immediately present itself before the eyes of man and the reality of the essence of man will be reflected by man itself. "Make man be man" means that man's relations are not established by alienating mediums by the likes of capital or money, but directly between man. A crisis of non-rationality is a holistic problem: The core of capital lies in movement, it makes rationality the only principle. The creation of this kind of principle doesn't need the acknowledgement of man, but stands on its own pre-conditions. The essence of the risk is that human beings are treated as commodities. And relations among people are measured by capital.

Capital is a collective product, and only by the united action of many members of society, can it be set in motion. This total estrangement from reality, apparently doesn't need any supporting self-control movement from within the real life. In regard to the essence, it only needs self-denial. And the power of denial is fueled by reality's each and every man. As the famous saying goes that "The proletarians have nothing to lose but their chains. They have a world to win. Proletarians of all countries, unite!”. 


\section{Reference}

David, H. (2013). A Companion to Marx's Capital (Vol. 2, Ver. 16).

Georg Wilhelm Friedrich Hegel. (1830). The Science of Logic (p. 25). Cambridge University Press.

Karl, M. (2002). Economic and Philosophic Manuscripts of 1844 (M. Milligan, Trans., p. 137).

Karl, M. (2004). Capital (Vol. 1, Zodiac et al. Trans., p. 104, pp. 153-155, pp. 877-878). China: Renmin Press. 